\title{
Reviewer Acknowledgements
}

Modern Applied Science wishes to acknowledge the following individuals for their assistance with peer review of manuscripts for this issue. Their help and contributions in maintaining the quality of the journal are greatly appreciated.

Modern Applied Science is recruiting reviewers for the journal. If you are interested in becoming a reviewer, we welcome you to join us. Please find the application form and details at http://recruitment.ccsenet.org and e-mail the completed application form to mas@ccsenet.org.

\section{Reviewers for Volume 11, Number 11}

Assad Omar, Al-Batra University, United Kingdom

Chanchai Chitlaoarporn, Rangsit University, Thailand

Christoph Maria Ravesloot, Rotterdam University of Applied Science, The Netherlands

Daniela Popescu, Technical University of Iasi, Romania

Efstathios Stefos, National University of Education (UNAE), Greece

Huda Samee, Zarqa Private University, Jordan

Hui Wan, Mississippi State University, USA

Janar Jarasovna, L.N.Gumilyov Eurasian National University, Kazakhstan

Jill Smith, University of York, United Kingdom

Maissarath Nassirou, Seagate technology, USA

Ningbo Li, Sunhai Bioadhesive Technologies LLC, USA

Peng Zhang, State University of New York at Stony Brook, United States

Praveen Kumar, Texas Tech University, United States

Pri Priyono, Economics Faculty Universities PGRI Adi Buana, Indonesia

Rostyslav Sklyar, Independent professional, Ukraine

S. M. Abrarov, York University, Canada

Sahar Ahmed Abdalbary, Department of orthopedic of physical therapy and its surgery, Egypt

Valter Aragao do Nascimento, Federal University of Mato Grosso do Sul, Brazil 